\title{
Rat injury model of docetaxel extravasation
}

\author{
JING-JING ZHU ${ }^{1}$, JIAN-FEI FU ${ }^{2}$, JIAO YANG ${ }^{3}$, BING HU $^{4}$, HUI ZHANG ${ }^{5}$ and JIAN-HUA YU ${ }^{2}$ \\ Departments of ${ }^{1}$ Rehabilitation and ${ }^{2}$ Oncology, Jinhua Central Hospital (Jinhua Hospital of Zhejiang University), \\ Jinhua, Zhejiang 321000; ${ }^{3}$ Cancer Institute, The Second Affiliated Hospital, \\ Zhejiang University School of Medicine, Hangzhou, Zhejiang 310009; \\ ${ }^{4}$ Department of Pathology, Jinhua Central Hospital (Jinhua Hospital of Zhejiang University); \\ ${ }^{5}$ Jinhua Food and Drug Administration, Jinhua, Zhejiang 321000, P.R. China
}

Received March 25, 2014; Accepted May 15, 2014

DOI: $10.3892 /$ br.2014.292

\begin{abstract}
Docetaxel is a novel type of chemotherapy drug that actively treats a number of malignant tumors. The aim of the present study was to explore the severity and natural course of tissue damage induced by docetaxel extravasation and to confirm the vesicant potential of docetaxel. Rats were selected for the establishment of the ulcer model. Different volumes and concentrations were explored to induce the skin ulcer and to confirm the optimum rational injection model. The natural course of tissue injury and pathological changes produced by docetaxel extravasation were observed by comparing to vinorelbine extravasation. A $0.4 \mathrm{ml}$ volume and a $6 \mathrm{mg} / \mathrm{ml}$ concentration were the optimum rational injection model for the induction of the skin ulcer. The docetaxel extravasation induced local tissue necrosis, followed by granuloma formation and hyperpigmentation or scar formation. The severity of the injury depended on the concentration of the extravasation used in the rat model. The injury occurred on the first day following extravasation and lasted 4-6 weeks. The damage from docetaxel was weaker than vinorelbine in association with the depth and extension of necrosis. In conclusion, docetaxel extravasation can induce tissue necrosis. However, the severity of necrosis was weaker than that of vinorelbine. Docetaxel has superficial vesicant properties.
\end{abstract}

\section{Introduction}

Docetaxel acts as a novel type of chemotherapy drug belonging to the taxane family. As a microtubule antagonist, docetaxel is active to a variety of malignant tumors, including breast cancer (1), non-small cell lung cancer (2), head and neck squamous carcinoma (3) and gastric cancer (4). Docetaxel is administered by intravenous infusion only. With the use of

Correspondence to: Dr Jian-Fei Fu, Department of Oncology, Jinhua Central Hospital (Jinhua Hospital of Zhejiang University), 351 Mingyue Street, Jinhua, Zhejiang 321000, P.R. China

E-mail: nuifu@sina.com

Key words: extravasation, docetaxel, skin toxicity, pathology a central line increasing, the incidence of extravasation has been on the decrease in recent years. As for patients with superior vena cava obstruction, dissection of the bilateral axilla lymph nodes or failure to place a central catheter, peripheral intravenous line should be considered. The incidence of chemotherapy drug extravasation has been reported as 11 and $22 \%$ in children and adults, respectively (5). The vesicant potential of anthrancyclines (6), vinorelbine (7)and paclitaxel (8) extravasation have been confirmed. In clinical practice, whether a vesicant reaction would be induced by docetaxel extravasation has been debated previously (9), and the management of docetaxel extravasation requires clarification. In the present study, docetaxel extravasation was studied in a rat model. This study was approved by the Ethics Committee of hospital and was performed according to the Declaration of Helsinki. Written informed consent was obtained from each patient's family.

\section{Materials and methods}

Animals and drugs. Female Sprague-Dawley white rats (weight, 300-350 g) were provided by Jinhua Food and Drug Administration (Jinhua, Zhejiang, China). Docetaxel (Taxotere) and vinorelbine (Novelbine) were produced by Sanofi Aventis (Paris, France) and Laboratories Pierre Fabre (Castres, France), respectively.

Injection model. The experimental rats were non per os for $24 \mathrm{~h}$, watered freely, weighed and subsequently received intraperitoneal anesthesia of pentobarbital sodium $(40 \mathrm{mg} / \mathrm{kg})$. The hair in the bilateral lower extremities was shaved with an electric shaver. An area of skin, $4 \mathrm{~cm}^{2}$ in diameter, was prepared. A needle $(1 \mathrm{ml})$ was used for the intradermal injection of the docetaxel solution. The standard of successful intradermal injection was defined as a $1-\mathrm{cm}$ diameter formation of a skin rash. Docetaxel, $20 \mathrm{mg}$ in $0.5 \mathrm{ml}$ polysorbate 80 , was diluted with $1.5 \mathrm{ml} 13 \%$ ethanol and stored at a $10 \mathrm{mg} / \mathrm{ml}$ concentration. Subsequently, normal saline (NS) was used for the dilution of docetaxel into numerous concentrations. Six levels of injection volumes were selected: $0.1,0.2,0.3,0.4$, 0.5 and $0.6 \mathrm{ml}$; and five levels of concentration injection were selected: 1, 2, 4, 6 and $8 \mathrm{mg} / \mathrm{ml}$. A total of eight rat models were assigned to each level. 
Table I. Areas and healing time of the ulcer in the different groups.

\begin{tabular}{lcccc}
\hline Groups & Ulcer formation, $\%$ & Areas under curve, $m^{2}$ & Peak area, mm & Healing time, days \\
\hline Docetaxel, $8 \mathrm{mg} / \mathrm{ml}$ & 100 & $1127.6 \pm 144.1^{\mathrm{a}, \mathrm{b}, \mathrm{c}}$ & $85.0 \pm 6.5^{\mathrm{a}, \mathrm{b}, \mathrm{c}}$ & $27.0 \pm 5.7^{\mathrm{a}, \mathrm{b}}$ \\
Docetaxel, $6 \mathrm{mg} / \mathrm{ml}$ & 100 & $806.8 \pm 97.8^{\mathrm{a}, \mathrm{b}}$ & $64.4 \pm 6.2^{\mathrm{a}, \mathrm{b}}$ & $23.0 \pm 2.0^{\mathrm{a}, \mathrm{b}}$ \\
Docetaxel, $4 \mathrm{mg} / \mathrm{ml}$ & 50 & $164.0 \pm 46.4$ & $37.1 \pm 5.3^{\mathrm{a}}$ & $13.5 \pm 2.4 .$. \\
Docetaxel, $2 \mathrm{mg} / \mathrm{ml}$ & 25 & $47.9 \pm 14.3$ & $14.1 \pm 1.2$. & $9.0 \pm 1.4$ \\
Vinorelbine & 100 & $1912.3 \pm 115.8^{\mathrm{d}}$ & $150.6 \pm 10.8^{\mathrm{d}}$ & $28.9 \pm 2.5^{\mathrm{d}}$. \\
\hline
\end{tabular}

${ }^{\mathrm{a}} \mathrm{Vs}$. docetaxel $2 \mathrm{mg} / \mathrm{ml}, \mathrm{P}<0.05 ;{ }^{\mathrm{b}} \mathrm{vs}$. docetaxel $4 \mathrm{mg} / \mathrm{ml}, \mathrm{P}<0.05 ;{ }^{\mathrm{c}} \mathrm{vs}$. docetaxel $6 \mathrm{mg} / \mathrm{ml}, \mathrm{P}<0.05$, with one-way analysis of variance; ${ }^{\mathrm{d}} \mathrm{vs}$. docetaxel $6 \mathrm{mg} / \mathrm{ml}, \mathrm{P}<0.05$, with independent-sample t-test.

Control groups. The intradermal injection of $0.4 \mathrm{ml} \mathrm{NS}$ (1-cm diameter skin rash formation) was considered to be the negative control group, and $0.4 \mathrm{ml}$ vinorelbine $(2 \mathrm{mg} / \mathrm{ml}$ concentration) was considered to be the positive control group. A total of eight rat models were assigned to each control group.

Observation of the injection site. The definition of a skin ulcer was epidermal excoriation and the loss of skin integrity. The definition of recovery was the disappearance of the ulcer, swelling and edema. The perpendicular widths of the skin ulcer were measured and multiplied to yield a lesion area. The ulcer area was measured each day from the day following extravasation and all areas were integrated to yield the area under the curve (AUC). The AUC, the peak area of the skin ulcer and the healing time were analyzed.

Pathological changes. The lesions induced by docetaxel and vinorelbine were biopsied on days 4, 7, 14, 21 and 28 after the initial injection. The entire samples, including the skin, subcutaneous tissue and muscle, in the lesion and surrounding healthy tissue were obtained and placed in $10 \%$ formaldehyde for fixation prior to dehydration, paraffin-embedding and hematoxylin and eosin staining. The pathological changes were evaluated by a pathologist who was not present during the experimental procedure.

Statistical analysis. The differences between the AUC, peak area and healing time among all levels of docetaxel concentrations were analyzed by one-way analysis of variance. If the variation was equal, the least significant difference test was used, and if it was not equal, Tamhane's T2 test was used. The differences of the AUC, peak area and healing time between $6 \mathrm{mg} / \mathrm{ml}$ of docetaxel and novelbine were analyzed by the t-test. $\mathrm{P}<0.05$ was considered to indicate a statistically significant difference. SPSS 16.0 statistical software (SPSS, Inc., Chicago, IL, USA) was used for data analysis.

\section{Results}

Optimal volume of injection. From 0.1 to $0.4 \mathrm{ml}$, the area of the skin rash was enlarged in correlation to the increasing injection volume. The $0.4 \mathrm{ml}$ volume elaborated a $1-\mathrm{cm}$ rash. Injection volumes $>0.4 \mathrm{ml}$ resulted in leakage of the solution out of the hair follicles. Therefore, the optimum volume of injection was confirmed as $0.4 \mathrm{ml}$. The skin rash and skin ulcer were not induced by subcutaneous injection.

Optimal concentration of injection. There was no change or subtle erythema in the injection site following a $1 \mathrm{mg} / \mathrm{ml}$ injection, and there was no skin ulcer formation observed. The incidence of docetaxel-induced ulcer formation was 25.0, $50.0,100$ and $100 \%$ for the injection of 2, 4, 6 and $8 \mathrm{mg} / \mathrm{ml}$ respectively. As for the AUC, there were statistical differences between the injection of 4, 6 and $8 \mathrm{mg} / \mathrm{ml}$. Statistical differences among all levels of injection were observed for the peak area. There were statistical differences for the healing times between the levels of 4, 6 and $8 \mathrm{mg} / \mathrm{ml}$ (Table I).

Natural course of the injury. Regarding the docetaxel extravasation, mild injury in the injection site presented as a subtle erythema, moderate injury was whitened skin surrounded by congestion and edema, and severe injury was necrosis. The peak area occurred on the day following the injection. On days 7-9, the epidermal tissue excoriated and the ulcer formed with black or white necrotic tissue covering the ulcer surface. The ulcer was strictly limited in the extension as observed on the day following the injection and did not expand as time increased. On day 21, the necrotic tissue in the bottom of the ulcer was absorbed and the granuloma began to grow rapidly. Ulcers were recovered on days 28-42 (Fig. 1). After 12 weeks, the sequelae presented with scar or hyperpigmentation in the injury skin.

As for the NS injection, there was no change observed in the injection site. The extension of necrosis expanded gradually in the positive control group with the vinorelbine injection, and the peak area of necrosis occurred on days 3-5 after injection. The AUC $\left(1912.3 \pm 115.8\right.$ vs. $\left.806.8 \pm 97.8 \mathrm{~mm}^{2}, \mathrm{P}<0.005\right)$ and peak area $\left(150.6 \pm 10.8\right.$ vs. $\left.64.4 \pm 6.2 \mathrm{~mm}^{2}, \mathrm{P}<0.005\right)$ were increased and the healing time $(28.9 \pm 2.5$ vs. $23.0 \pm 2.0$ days, $\mathrm{P}<0.005)$ was longer than that of the $6 \mathrm{mg} / \mathrm{ml}$ docetaxel concentration (Table I).

Pathological changes. In the first two weeks following injection, epidermal and dermal degeneration were observed. The fatty necrosis and dissolution, and diffuse nuclear debris were observed in the subcutaneous tissue. There were nuclear debris and inflammatory cells identified in the surficial muscles. The hair follicle, sweat gland and sebaceous gland were damaged. In the 3rd week, granuloma tissue formed and necrotic tissue 


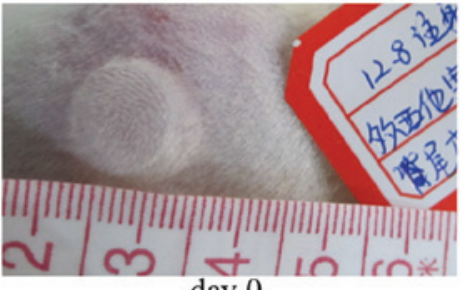

day 0

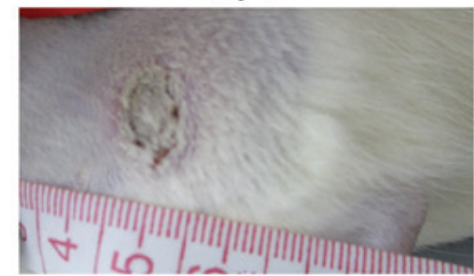

day 14

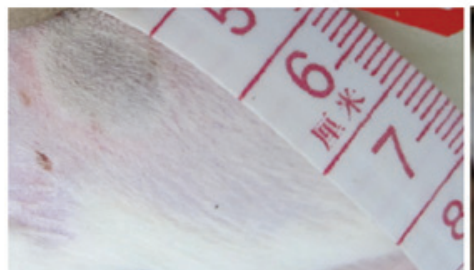

day 4

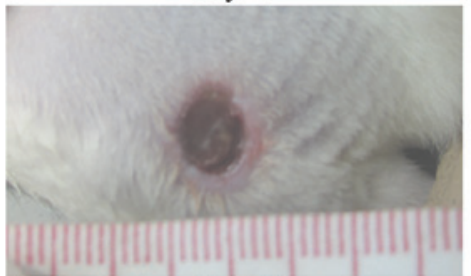

day 21

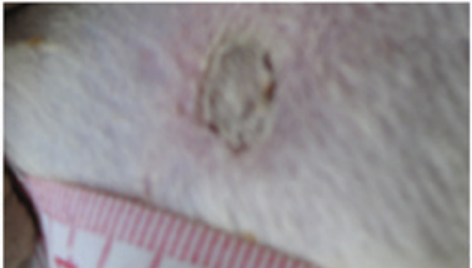

day 7

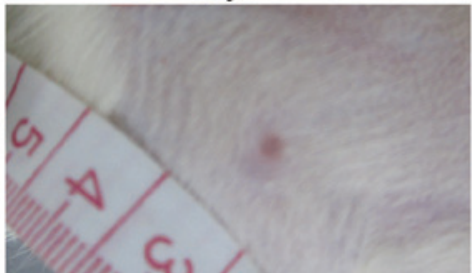

day 28

Figure 1. Skin injury induced by $6 \mathrm{mg} / \mathrm{ml}$ docetaxel. On day 0 , a 1-cm skin rash was created in the injection site. By day 4 , the skin had turned black and presented with necrosis of subcutaneous tissue. On day 7 the ulcer had formed, with a surface covered by white necrotic tissue, which will be persisted until day 14. By day 21, the necrotic tissue had excoriated and granuloma had formed. On day 28 the lesion of skin had recovered.

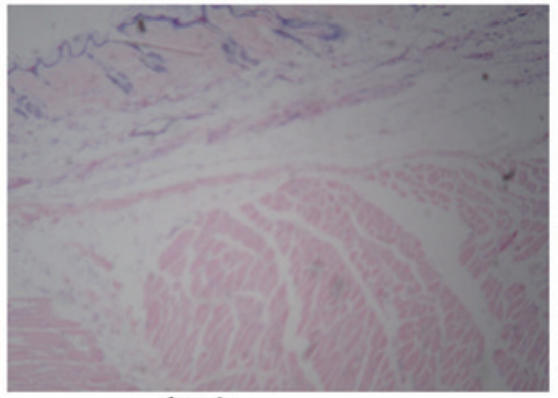

day 0

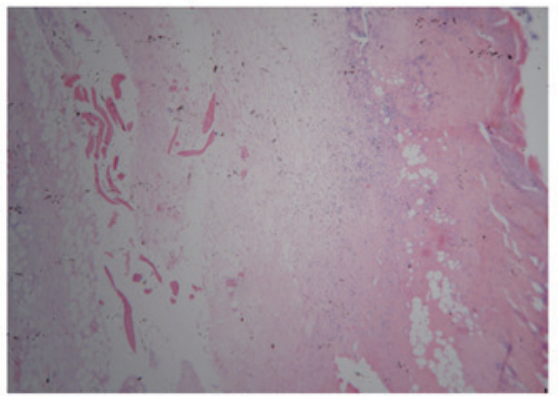

day 14

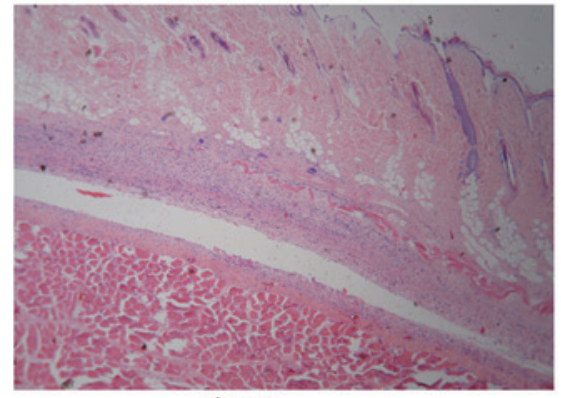

day 4

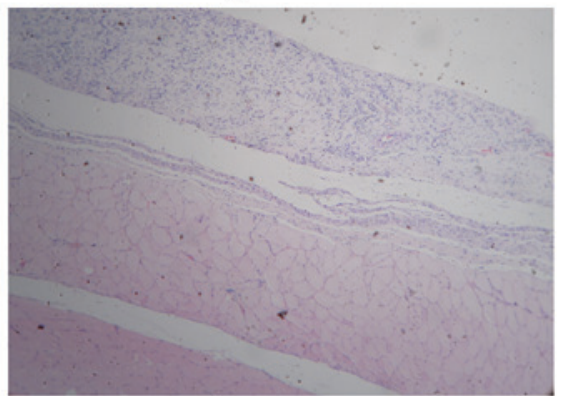

day 21

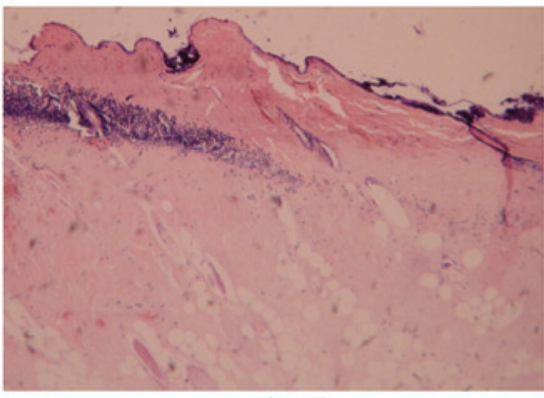

day 7

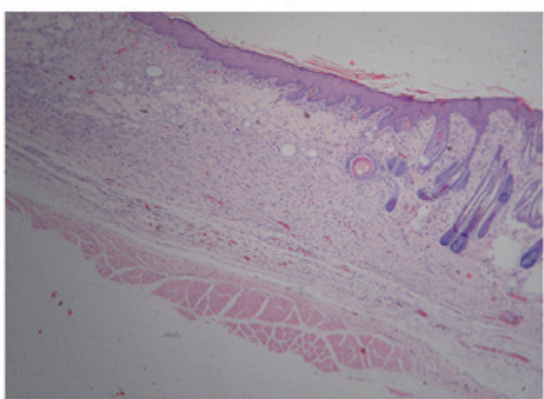

day 28

Figure 2. Pathological changes induced by docetaxel extravasation. Hematoxylin and eosin stain; magnification, x50. Day 0 presents the normal skin. On day 4 , the epidermal, dermis and subcutaneous tissue presented with degeneration and necrosis. Day 7, the main pathological change presented with necrosis. Part of the epidermis had excoriated and the integrity of the epidermis was damaged. Day 14, the main change remained as necrosis, and the surficial muscle was involved. Some nuclear debris and inflammatory cells infiltrated into the muscles. Day 21, the necrosis was absorbed and granuloma formed. By day 28 the epidermis had regenerated and the integrity of the epidermis was recovered again. The hair follicle hyperplasia was obvious.

was absorbed. In the 4th week, the epidermis and appendix of the skin regenerated (Fig. 2). In the 12th week, the scar was formed. As for extravasation of the injected vinorelbine, a reverse-breaker-like ulcer formed, which deepened into the muscles in the first two weeks.

\section{Discussion}

At a low concentration $(1 \mathrm{mg} / \mathrm{ml})$, the extravasation of docetaxel failed to induce a skin ulcer in a rat model. Concentrations of 2 and $4 \mathrm{mg} / \mathrm{ml}$, formed an irregular ulcer. The severity of the skin damage was associated with a higher concentration. The equal concentration of docetaxel injected into the dermis rather than the subcutaneous layer induced a skin ulcer. However, whether the ulcer formation was associated with the injected concentration and local anatomy component remains to be elucidated. The peak area occurred on the day following the injection, which indicates that docetaxel would not cause a delayed damage and expand into the surrounding tissue in the rat model.

In clinical practice, there have been numerous debates with regards to the vesicant potential of docetaxel extravasa- 
tion. A study by Gallo et al (10) reported that three patients who encountered the docetaxel extravasation presented with a severe irritant reaction. Kramer et al (11) and Ley et al (12) also reported that docetaxel extravasation induced the skin recall phenomenon. In these studies, the initial symptom of docetaxel extravasation was irritant reaction. By contrast, other studies (13-19) have indicated that docetaxel was a surficial vesicant drug. In the study by Cifuentes et al (13), the ultrasonic image indicated change in cell lysis in the subcutaneous layer. Berghammer et al (17) and Chu et al (20) described that docetaxel extravasation induced the tissue necrosis and nerve injury. The sequelea of the feeling of skin paralysis was reported $(18,20)$.

In clinical practice, when $250 \mathrm{ml} \mathrm{NS}$ is used to dilute docetaxel, the concentration is $\sim 0.2 \mathrm{mg} / \mathrm{ml}$ in the weekly regime $\left(25 \mathrm{mg} / \mathrm{m}^{2}\right)$ and $0.5 \mathrm{mg} / \mathrm{ml}$ in 3 -week regime $\left(75 \mathrm{mg} / \mathrm{m}^{2}\right)$. However, these concentrations, which are much lower than $1 \mathrm{mg} / \mathrm{ml}$, failed to induce an ulcer in the rat model of the present study. The ulcer formation is not only associated with the concentration and volume of extravasation, but also with the speed and site of extravasation. In addition, once the docetaxel is adversely extravasated, treatment is provided immediately, which also impacts the ulcer formation. All these factors may be explanations for the observed contradictions between the rat model and clinical practice. A study by Raley et al (18) indicated the delayed vesicant-type reaction of docetaxel extravasation. The study by El Saghir and Otrock (15) identified that docetaxel extravasated into the normal breast when administrated by infusion with a central line. The extent of the skin injury expanded gradually. The phenomenon of the delayed reaction and expanded damage was contradicted with the rat model of the present study.

In the rat model, pathological changes of docetaxel extravasation are potentially described in three phases: The necrosis/lysis, granuloma repair and cure phases. Fatty necrosis and dissolution, and granuloma formation were first described in the study. Docetaxel did not induce a reverse-breaker-like ulcer, which was characteristic of vinorelbine extravasation. The extension of the ulcer induced by docetaxel extravasation was smaller compared to vinorelbine induction. The depth of necrosis induced by docetaxel extravasation was more surficial compared to vinorelbine, and the muscle impact was weaker. The pathological changes were further confirmed to have a surficial vesicant property of docetaxel. Previous studies have indicated that the pathological changes included dyskeratotic keratinocytes, the bubble of the basal cell $(10,12,20)$. These changes were not observed in the rat model. The sequelea of the docetaxel extravasation was scar formation or hyperpigmentation, which is similar to reported clinical studies $(14,15)$.

In conclusion, the extravasation of a high concentration docetaxel can induce tissue necrosis, and the severity is weaker compared to induction by vinorelbine. Docetaxel is a surficial vesicant agent, and it is essential that docetaxel extravasation is prevented in the clinical practice.

\section{Acknowledgements}

The present study was supported by grants from the Jinhua Municipal Science Technology Department (grant no. 2011-3-032).

\section{References}

1. Mackey JR, Martin M, Pienkowski T, et al; TRIO/BCIRG 001 investigators: Adjuvant docetaxel, doxorubicin, and cyclophosphamide in node-positive breast cancer: 10-year follow-up of the phase 3 randomised BCIRG 001 trial. Lancet Oncol 14: 72-80, 2013.

2. Fossella F, Pereira JR, von Pawel J, et al: Randomized, multinational, phase III study of docetaxel plus platinum combinations versus vinorelbine plus cisplatin for advanced non-small-cell lung cancer: the TAX 326 study group. J Clin Oncol 21: 3016-3024, 2003.

3. Vermorken JB, Remenar E, van Herpen C, et al; EORTC 24971/ TAX 323 Study Group: Cisplatin, fluorouracil, and docetaxel in unresectable head and neck cancer. N Engl J Med 357: 1695-1704, 2007.

4. Van Cutsem E, Moiseyenko VM, Tjulandin S, et al; V325 Study Group: Phase III study of docetaxel and cisplatin plus fluorouracil compared with cisplatin and fluorouracil as first-line therapy for advanced gastric cancer: a report of the V325 Study Group. J Clin Oncol 24: 4991-4997, 2006.

5. Yilmaz M, Demirdover C and Mola F: Treatment options in extravasation injury: an experimental study in rats. Plast Reconstr Surg 109: 2418-2423, 2002.

6. Bowers DG Jr and Lynch JB: Adriamycin extravasation. Plast Reconstr Surg 61: 86-92, 1978.

7. Dorr RT and Bool KL: Antidote studies of vinorelbine-induced skin ulceration in the mouse. Cancer Chemother Pharmacol 36: 290-292, 1995.

8. Dorr RT, Snead K and Liddil JD: Skin ulceration potential of paclitaxel in a mouse skin model in vivo. Cancer 78: 152-156, 1996.

9. Payne AS, James WD and Weiss RB: Dermatologic toxicity of chemotherapeutic agents. Semin Oncol 33: 86-97, 2006.

10. Gallo E, Llamas-Velasco M, Navarro R, Fraga J and García-Diez A: Eccrine squamous syringometaplasia secondary to cutaneous extravasation of docetaxel: report of three cases. J Cutan Pathol 40: 326-329 2013.

11. Kramer F, Schippert C, Rinnau F, Hillemanns P and Park-Simon TW: The first description of docetaxel-induced recall inflammatory skin reaction after previous drug extravasation (February). Ann Pharmacother: Jan 25, 2011 (Epub ahead of print).

12. Ley BD, Millán GG, Perez JS, Fraga J and Díez AG: Docetaxel recall phenomenon at the site of previous drug extravasation. Arch Dermatol 146: 1190-1191, 2010.

13. Cifuentes L, Ring J and Brockow K: Extravasation of docetaxel. J Dtsch Dermatol Ges 10: 662-663, 2012 (In English, German).

14. Barceló R, Viteri A, Muñoz A, Carrera S, Rubio I and López-Vivanco G: Extravasation of docetaxel: a red hand syndrome. Arch Dermatol 141: 1326-1327, 2005.

15. El Saghir NS and Otrock ZK: Docetaxel extravasation into the normal breast during breast cancer treatment. Anticancer Drugs 15: 401-404, 2004.

16. Ho $\mathrm{CH}$, Yang $\mathrm{CH}$ and $\mathrm{Chu} \mathrm{CY}$ : Vesicant-type reaction due to docetaxel extravasation. Acta Derm Venereol 83: 467-468, 2003.

17. Berghammer P, Pöhnl R, Baur M and Dittrich C: Docetaxel extravasation. Support Care Cancer 9: 131-134, 2001.

18. Raley J, Geisler JP, Buekers TE and Sorosky JI: Docetaxel extravasation causing significant delayed tissue injury. Gynecol Oncol 78: 259-260, 2000.

19. Ascherman JA, Knowles SL and Attkiss K: Docetaxel (taxotere) extravasation: a report of five cases with treatment recommendations. Ann Plast Surg 45: 438-441, 2000.

20. Chu CY, Yang CH, Yang CY, Hsiao GH and Chiu HC: Fixed erythrodysaesthesia plaque due to intravenous injection of docetaxel. Br J Dermatol 142: 808-811, 2000. 